\title{
POTENSI KOMUNITAS MANGROVE PANTAI TIAL KABUPATEN MALUKU TENGAH
}

\section{(Potency of Mangrove Community on Tial Coastal Waters, Central Maluku Regency)}

\author{
R. Pentury, J. H. Pietersz*, M. A. Tuapattinaja, F. S Pello, N. V. Huliselan, M. Hulopi \\ dan Ch. I. Tupan
}

\begin{abstract}
Jurusan Manajemen Sumberdaya Perairan Fakultas Perikanan dan Ilmu Kelautan Universitas Pattimura rpentury0508@gmail.com,*jansonpietersz.1301@gmail.com,mkaihatu@gmail.com, rikapello@yahoo.com, nietteh@yahoo.com,mhulopi75@gmail.com,lotjetupan@yahoo.com Corresponding author*
\end{abstract}

\begin{abstract}
ABSTRAK: Komunitas mangrove merupakan komunitas yang cukup potensial dan memiliki peranan penting bagi organisme perairan sekitar dan bagi masyarakat setempat, terutama dalam mengendalikan abrasi pada pesisir pantai Tial. Laju abrasi yang terjadi pada pesisir pantai Negeri Tial cukup tinggi, sehingga keberadaan mangrove pada perairan tersebut perlu dijaga dan dilestarikan. Tujuan dari penelitian ini adalah untuk mengetahui komposisi, Potensi dan kondisi mangrove di perairan pantai Tial. Metode yang digunakan yaitu metode transek sabuk dan hemisperichal photography. Metode ini dilakukan dengan cara menentukan stasiun pengamatan, kemudian pada setiap stasiun pengamatan dibentuk petak pengamatan sebesar $10 \times 10 \mathrm{~m}$ sebanyak tiga petak tanpa ada jarak antara petak pengamatan. Pada setiap petak pengamatan dilakukan pengambilan lingkar batang dengan ukuran $\geq 15 \mathrm{~cm}$ dan pengambilan foto kanopi dengan memotret setinggi dada secara tegak lurus kearah atas. Software Microsoft Excel dan Image $J$ digunakan untuk menganalisis data pengukuran lingkar batang dan hasil foto kanopi. Dari hasil analisis diperoleh 9 spesies mangrove yang tergolong dalam 7 genera dan 5 famili. Sonneratia alba dan Aegiceras floridum merupakan spesies mangrove yang mendominasi komunitas mangrove pantai Tial. Kerapatan spesies tertinggi adalah A. floridum sebesar 13 ind $/ 100 \mathrm{~m}^{2}$, sedangkan frekuensi kehadiran dan dominasi spesies tertinggi adalah $S$. alba dengan nilai masing-masing 0,67 dan 2298,75 $\mathrm{cm}^{2} / 100 \mathrm{~m}^{2}$. Kondisi kesehatan mangrove secara keseluruhan pada pantai Tial masih dalam kondisi baik dengan kerapatan mangrove tergolong padat dan tutupan kanopi tergolong sedang.
\end{abstract}

Kata Kunci: mangrove, potensi, komunitas, kesehatan, pantai

ABSTRACT: Mangrove community in Tial is potential and roles importantly for aquatic organism, local community and especially for coastal waters abrasion control in Tial. Due to the high rate abrasion in Tial, mangrove community should be maintained and conserved. Therefore, the research is done in order to analyze mangrove composition, its potency and its condition on the coast of Tial. Belt transect and hemispherical photography method are used to collect data by determining the observation station. Three plots of $10 \times 10$ meter squares are placed in every observation station without space in between each plot where the $\geq 15$ $\mathrm{cm}$ of circumference trees measuring is done and canopy photo of breast height are taken up above perpendicularly. Microsoft Excel and Image $\mathbf{J}$ software are used to analyze collected data. The result shows that there are 9 species of mangrove from 7 genera and 5 families found in the coast of Tial. Sonneratia alba and Aegiceras floridum dominates the community where A. floriduim with $13 \mathrm{ind} / 100 \mathrm{~m}^{2}$ is the highest density species, while the frequency of occurrence and the highest dominance species is $S$. alba with the rate 0,67 and 2298,75 
$\mathrm{cm}^{2} / 100 \mathrm{~m}^{2}$. Overall mangrove vegetation health is categorized good with a high density and in a medium canopy coverage.

Keywords: mangrove, potency, community, health, coastal

\section{PENDAHULUAN}

Wilayah pesisir memiliki potensi sumberdaya yang cukup tinggi dengan keberadaan tiga eksositem penting didalamnya (Sjafrie, 2016; Sambah, dkk., 2019). Salah satu ekosistem penting pada wilayah pesisir yaitu ekosistem mangrove. Mangrove memiliki peranan penting bagi manusia maupun organisme biotik lainnya. Mangrove merupakan ekosistem peralihan antara darat dan laut yang mempunyai nilai ekologis, fisik maupun ekonomis yang tinggi (Takarendehang, $d k k$., 2018; Lugina, $d k k$., 2019). Selain menghasilkan bahan dasar untuk memenuhi kebutuhan manusia skala kecil dan industri seperti kayu bakar, arang dan kertas, mangrove juga memiliki fungsi-fungsi ekologis penting antara lain sebagai penyedia unsur hara, sebagai tempat pemijahan, pengasuhan dan mencari makan bagi berbagai biota laut. Secara fisik Mangrove juga mampu berperan dalam mengendalikan abrasi pada wilayah pesisir sehingga kestabilan garis pantai tetap terjaga (Widagdo\&Sugiri, 2014).

Hutan mangrove di kawasan Teluk Ambon sangat mendukung pembangunan dan perlindungan di Kota Ambon. Pada tahun 1999, luas hutan mangrove mengalami pengurangan 4 ha. Laju deforestasi dari tahun 1999 hingga tahun 2006 sekitar 0,67 ha per tahun (Suyadi, 2009). Selanjutnya dikatakan bahwa hilangnya kawasan hutan mangrove tersebut diakibatkan oleh konversi hutan mangrove menjadi pemukiman dan lahan pertanian. Berdasarkan hasil penelitian (Madiama, $d k k ., 2016$ ) diperoleh telah terjadi perubahan luas hutan mangrove di Kecamatan Teluk Ambon Baguala. Pada tahun 2005 luas hutan mangrove 41.955 ha menurun menjadi 37.651 ha di tahun 2009 atau $10.25 \%$. Pada tahun 2014 luasan mangrove tersebut menjadi 31.379 ha dengan luas perubahan sebesar 6.272 ha atau $16.65 \%$. Perubahan luasan mangrove tersebut akan terus terjadi mengingat tingginya aktivitas pembukaan lahan pesisir untuk pemukiman penduduk di daerah tersebut.

Komunitas mangrove pada perairan pantai Negeri Tial Kabupaten Maluku Tengah Pulau Ambon, merupakan komunitas yang cukup potensial dan memiliki peranan yang sangat penting bagi organisme biotik perairan sekitar, bagi masyarakat setempat dan yang paling utama yaitu dalam mengendalikan abrasi pada pesisir pantai Tial. Pemanfaatan hutan mangrove secara langsung oleh masyarakat seperti untuk kayu bakar memang sangat minim dilakukan. Pentingnya keberadaan mangrove di Negeri Tial difokuskan pada penahan gelombang laut agar tidak terjadi abrasi. Laju abrasi yang terjadi pada pesisir pantai Negeri Tial cukup tinggi, sehingga keberadaan mangrove pada perairan tersebut perlu dijaga dan dilestarikan. Menurut DAI (2018), bahwa wilayah di kepulauan Lease dan Ambon memiliki resiko tinggi terhadap abrasi. Berdasarkan beberapa hasil penelitian telah terjadi kemudnuran garis pantai pada Desa Rutong (Wattimena\&Ayal, 2018) dan Desa Seri Kota Ambon (Lilimwelat, $d k k$., 2019) akibat erosi pantai. Pantai Negeri Tial merupakan pantai semi terbuka dan berhadapan langsung dengan perairan laut Banda sehingga pantai tersebut dapat diterpa oleh ombak besar yang disebabkan hebusan angin dari laut Banda pada saat muson timur. Terpaan gelombang yang besar dapat menyebabkan kerusakan material pantai termasuk mangrove (Saru, 2014). Tujuan dari penelitian ini adalah untuk mengetahui komposisi spesies, potensi dan kondisi mangrove perairan pantai Tial.

\section{METODE PENELITIAN}

Penelitian ini dilaksanakan pada bulan Agustus 2019, pada perairan pantai Negeri Tial, Kabupaten Maluku Tengah, Pulau Ambon (Gambar 1). Data kondisi lingkungan perairan 
meliputi temperatur, salinitas, dan kondisi substrat dasar komunitas mangrove diukur secara in situ pada tiga titik di setiap stasiun pengamatan. Suhu air diukur dengan termometer batang, salinitas air diukur dengan refraktometer dan kondisi substrat pada komunitas mangrove diamati secara visual sepanjang jalur-jalur transek.

Pengumpulan data potensi mangrove dilakukan dengan metode transek sabuk (English, et al., 1997), metode hemisperichal photography yang dimodifikasi untuk mengetahui persentasi tutupan kanopi (Jenning, et al., 1999; Chianucci, et al., 2014; Dharmawan\&Pramudji, 2014), dan metode koleksi bebas untuk mengetahui potensi jenis mangrove yang tidak ditemukan di jalur pengamatan. Prosedur pengamatan dan pengambilan data mangrove di lapangan dilakukan dengan cara menentukan stasiun pengamatan yang dapat mewakili setiap area pengamatan. Pada setiap stasiun pengamatan dibuat petak pengamatan dengan ukuran 10 x 10 $\mathrm{m}$ sebanyak tiga petak, tanpa ada jarak antara petak satu dan lainnya. Pada setiap petak pengamatan dilakukan pengambilan data lingkar batang dengan ukuran $\geq 15 \mathrm{~cm}$ (Dharmawan\&Pramudji, 2014) dan pengambilan foto kanopi pohon secara tegak lurus ke arah atas (Chianucci, et al., 2014).

Sampel vegetasi mangrove yang diambil di lapangan, selanjutnya diidentifikasi jenisnya dan diklasifikasikan mengikuti Tomlinson (1986); Kitamura, et al., (1999); Giesen, et al., (2006); Rusila, et al., (1999); FAO (2007) dan Spalding, et al., (2010). Data lapangan meliputi jumlah tegakan dan diameter pohon setiap jenis, selanjutnya dianalisis untuk mendapatkan nilai kerapatan, frekuensi, dominansi dan indeks nilai penting yang menggambarkan struktur komunitas mangrove. Formula yang digunakan merujuk pada English, et al., (1997) dan Bengen (2001), sebagai berikut:

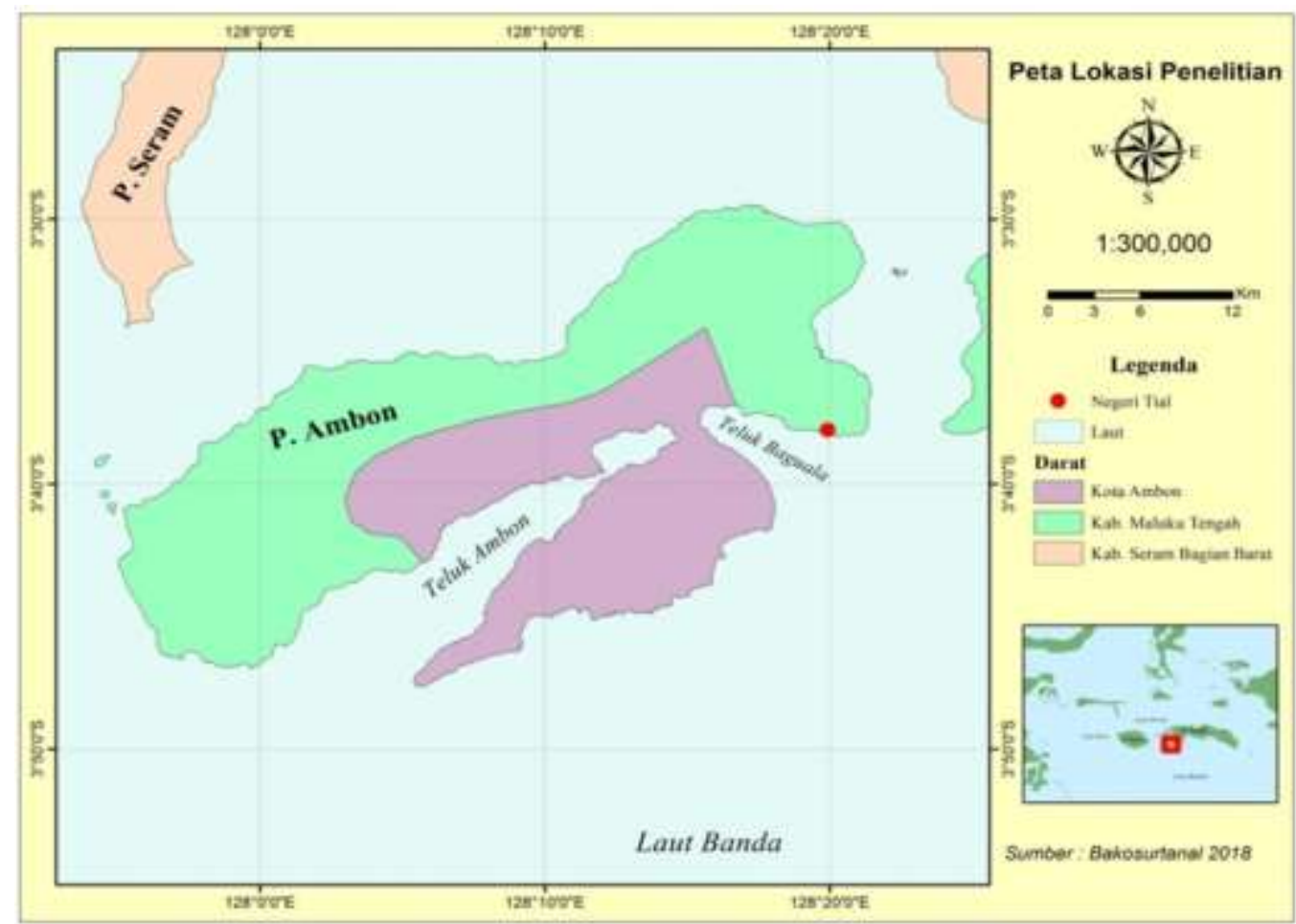

Gambar 1. Peta lokasi penelitian 


$\begin{array}{lll}\text { Kerapatan } & = & \frac{\text { Cacah individu suatu jenis }}{\text { Luas petak contoh }} \\ \begin{array}{l}\text { Kerapatan } \\ \text { Relatif }\end{array} & =\frac{\text { Densitas suatu jenis }}{\text { Densitas seluruh jenis }} \times 100 \% \\ \text { Frekuensi } & =\frac{\text { Cacah petak ditemukan suatu jenis }}{\text { Cacah seluruh petak }} \\ \begin{array}{l}\text { Frekuensi } \\ \text { Relatif }\end{array} & =\frac{\text { Frekuensi suatu jenis }}{\text { Frekuensi seluruh jenis }} \times 100 \% \\ \text { Dominansi } & = & \frac{\text { Cacah Basal Area }}{\text { Luas Petak contoh }} \\ \begin{array}{l}\text { Dominansi } \\ \text { Relatif }\end{array} & = & \text { Dominansi suatu jenis } \\ \text { Dominansi seluruh jenis } & \text { Dominansi Rel }+ \text { Frekuensi Rel } \\ \text { Nilai Penting } & = & \text { Dominansi Rel }\end{array}$

Berdasarkan hasil foto kanopi, selanjutnya dilakukan analisis pemisahan pixel langit dan tutupan vegetasi, agar persentasi jumlah pixel tutupan vegetasi mangrove dapat dihitung dengan menggunakan perangkat lunak Image $\mathrm{J}$ (Dharmawan\&Pramudji, 2014). Analisis kerapatan berdasarkan data jumlah tegakan mangrove dilakukan untuk menentukan kondisi kesehatan mangrove. Analisis data ini menggunakan formula menurut English, et al., (1997) dan Kepmen Lingkungan Hidup RI No. 201 Tahun 2004, sebagai berikut :

Kerapatan $\left(\frac{\text { ind }}{\text { ha }}\right)=\frac{\sum \text { tegakan suatu jenis x } 1000}{\text { Luas Petak Contoh }}$

Berdasarkan hasil analisis nilai kerapatan dan tutupan mangrove, selanjutnya dilakukan penilaian kesehatan mangrove yang didasarkan atas tabel baku mutu kesehatan mangrove yang merujuk pada Keputusan
DOI: https://doi.org/10.30598/TRITONvol16issue2page68-76

Menteri Lingkungan Hidup No. 201 Tahun 2004 (Tabel 1).

\section{HASIL DAN PEMBAHASAN}

\section{Lokasi Penelitian}

Negeri Tial terletak di Kecamatan Salahutu, Kabupaten Maluku Tengah, Propinsi Maluku. Perairan Negeri ini memiliki daerah pesisir dengan tipe semi terbuka yang berhadapan dengan perairan laut Banda, sehingga mendapat hempasan gelombang yang besar pada saat muson timur. Angin musim timur (muson timur) di Indonesia selalu terjadi pada belahan bumi selatan, dimana arah angin berasal dari Benua Australia yang mengarah ke Benua Asia dan terjadi pada bulan Juni-Agustus (Sudarto, 2011).

Besarnya gelombang pada pesisir pantai Negeri Tial ternyata tidak dapat menghambat kehadiran komunitas mangrove pada beberapa area di lokasi tersebut. Terdapatnya Barrier batuan pada sebagian area pesisir pantai Negeri Tial, menyebabkan vegetasi mangrove dapat tumbuh dengan baik karena memiliki perlindungan terhadap hempasan gelombang besar. Distribusi komunitas mangrove pada pantai Negeri Tial juga tidak merata dan mengalami fragmentasi yang disebabkan oleh sebaran Barrier yang tidak merata juga serta kondisi substrat yang berbeda-beda. Berdasarkan perbedaan tersebut, maka ditentukan empat stasiun untuk mewakili setiap area mangrove yang terfragmentasi (Gambar 2). Lokasi stasiun pengamatan secara astronomis terletak pada koordinat yang ditunjukan pada Tabel 2. Komunitas mangrove pantai Tial secara keseluruhan memiliki luas area sebesar $\pm 0,53$ ha.

Tabel 1. Kriteria baku kerusakan mangrove (Menteri LH No. 201 tahun 2004)

\begin{tabular}{rccc}
\hline & Kriteria & Penutupan $(\%)$ & Kerapatan (Pohon/ha) \\
\hline \multirow{2}{*}{ Baik } & Sangat Padat & $\geq 75$ & $\geq 1500$ \\
Rusak & Sedang & $\geq 50-<75$ & $\geq 1000-<1500$ \\
\hline
\end{tabular}


Tabel 2. Posisi stasiun pengamatan komunitas mangrove pantai Negeri Tial

\begin{tabular}{cccc}
\hline \multirow{2}{*}{ No } & Stasiun & \multicolumn{2}{c}{ Koordinat } \\
\cline { 3 - 4 } & & Bujur & Lintang \\
\hline 1 & I & $128^{\circ} 21^{\prime} 4,40^{\prime \prime}$ & $3^{\circ} 38^{\prime} 4,76^{\prime \prime}$ \\
2 & II & $128^{\circ} 20^{\prime} 49,11^{\prime \prime}$ & $3^{\circ} 38^{\prime} 9,38^{\prime \prime}$ \\
3 & III & $128^{\circ} 20^{\prime} 48,20^{\prime \prime}$ & $3^{\circ} 38^{\prime} 9,94^{\prime \prime}$ \\
4 & IV & $128^{\circ} 20^{\prime} 46,30^{\prime \prime}$ & $3^{\circ} 38^{\prime} 9,75^{\prime}$ \\
\hline
\end{tabular}

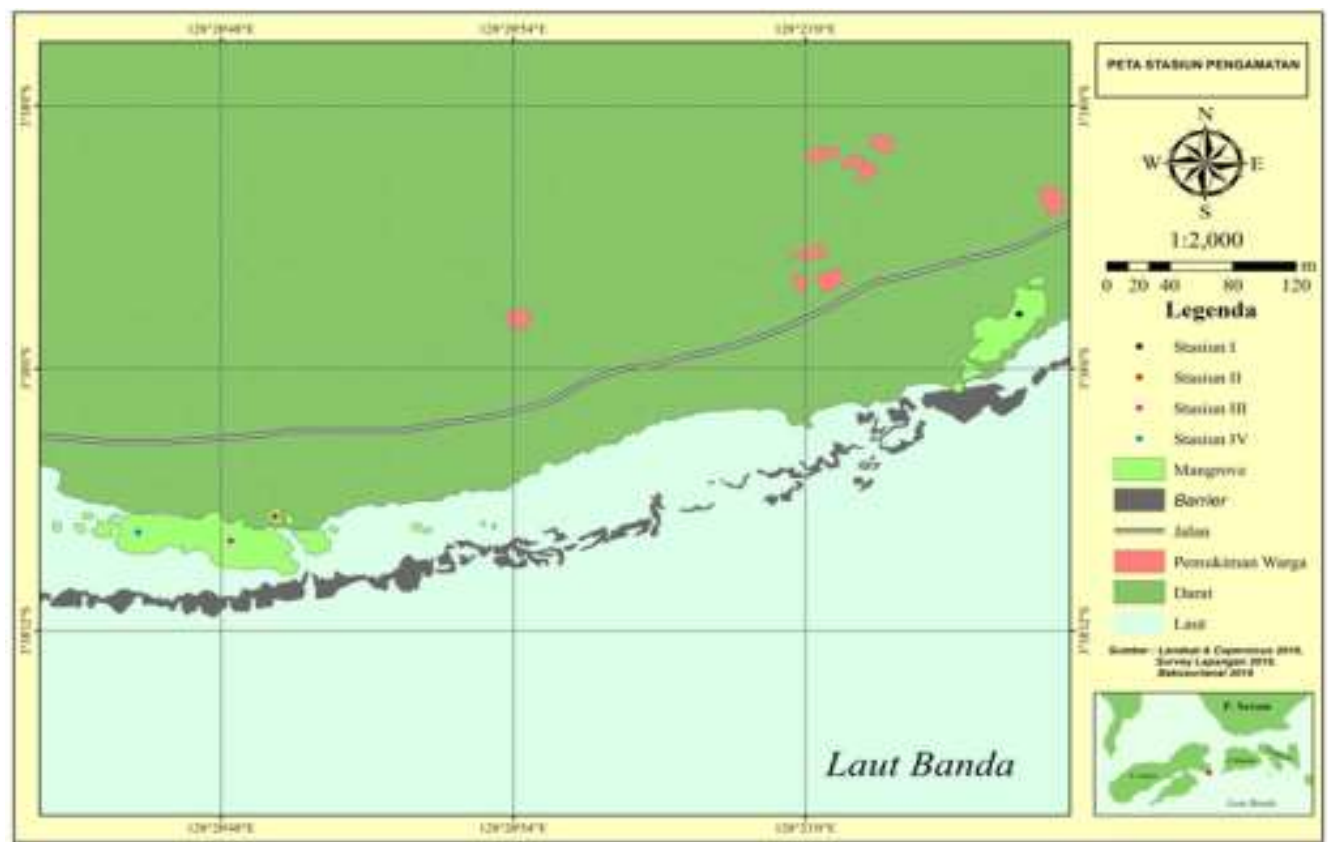

Gambar 2. Peta stasiun pengamatan komunitas mangrove pantai Negeri Tial

\section{Kondisi Lingkungan}

Kondisi lingkungan sangat mempengaruhi pertumbuhan mangrove (de Pannier\&Pannier, 2008). Hasil analisis beberapa parameter lingkungan perairan menunjukan salinitas pada komunitas mangrove pantai Negeri Tial berkisar antara 30-31\%o. Tidak adanya suplai air tawar secara konstan, seperti tidak adanya sungai dan mata air dari aliran ground water di sekitar komunitas mangrove menyebabkan kisaran salinitas cukup tinggi. Suplai air tawar pada komunitas mangrove terjadi melalui proses aliran run off saat terjadinya hujan. Sedangkan kondisi suhu pada komunitas mangrove pantai Negeri Tial memiliki kisaran yang beragam. Parameter suhu di luar tutupan kanopi memiliki nilai yang sama pada setiap stasiun pengamatan yaitu $29^{\circ} \mathrm{C}$ dan suhu di bawah tutupan kanopi berkisar diantara $27^{\circ} \mathrm{C}-28^{\circ} \mathrm{C}$. Parameter fisik lingkungan meliputi suhu, salinitas dan $\mathrm{pH}$ sangat mempengaruhi perkembangan tumbuh mangrove. Hal ini mempengaruhi sistem metabolisme maupun transport nutrient yang terjadi baik di tanah maupun air (Chrisyariati, $d k k ., 2014)$.

Hasil pengamatan secara visual terhadap kondisi substrat pada area stasiun I menunjukan distribusi substrat yang lebih beragam bila dibandingkan dengan area stasiun yang lain. Pada area stasiun I ditemukan tiga tipe substrat yaitu berpasir, pasir berlumpur dan berbatu. Kemudian pada area stasiun II, III, Dan IV hanya ditemukan dua tipe substrat yang sama yaitu berpasir dan berbatu.

\section{Komposisi Spesies Mangrove}

Berdasarkan hasil penelitian diperoleh 9 spesies mangrove yang tergolong dalam 7 genera dan 5 famili pada komunitas mangrove Pantai Tial (Tabel 3). Pada kesembilan spesies 
mangrove yang ditemukan terdapat enam spesies yang berada dalam petak pengamatan, sedangkan tiga spesies lainnya berada di luar petak pengamatan. Ketiga spesies yang ditemukan di luar kotak pengamatan adalah Bruguiera gymnorrhiza, Scyphiphora hyrophyllacea dan Rhizophora apiculata. Ketiga spesies ini ditemukan masing masing hanya satu individu yang tumbuh pada bagian tepi area pengamatan, sehingga tidak ditemukan di dalam petak pengamatan.

\section{Potensi Mangrove}

Hasil analisis potensi mangrove (Tabel 4) menunjukkan bahwa, Aegiceras floridum merupakan spesies dengan kerapatan tertinggi yaitu $13 \mathrm{ind} / 100 \mathrm{~m}^{2}(40,73 \%)$, diikuti oleh Ceriops tagal dengan nilai 6 ind $/ 100 \mathrm{~m}^{2}$ $(18,80 \%)$ serta Rhizophora stylosa dengan nilai 4,17 ind $/ 100 \mathrm{~m}^{2}(13,05 \%)$. Sedangkan spesies Scyphiphora hydrophyllacea dan Aegiceras corniculatum merupakan spesies dengan nilai kerapatan terendah yaitu sebesar $2,50 \mathrm{ind} / 100 \mathrm{~m}^{2}$ $(7,83 \%)$.

Spesies yang memiliki distribusi yang tinggi pada seluruh petak pengamatan adalah Sonneratia alba dengan nilai frekuensi kehadiran sebesar 0,67 (25,81\%), kemudian di ikuti oleh Aegiceras floridum sebesar 0,58 $(22,58 \%)$ dan Ceriops tagal sebesar 0,50 (19,35\%). Sedangkan spesies dengan kehadiran terendah adalah Aegiceras corniculatum dengan nilai frekuensi kehadiran sebesar $0,17(6,45 \%)$. Dominansi spesies mangrove berdasarkan luas basal area batang, spesies Sonneratia alba merupakan spesies yang memiliki nilai dominansi tertinggi sebesar $2298,78 \mathrm{~cm}^{2} / 100 \mathrm{~m}^{2}$ (60,67\%), kemudian diikuti oleh spesies Aegiceras floridum dengan nilai dominansi sebesar $832,50 \mathrm{~cm}^{2} / 100 \mathrm{~m}^{2}(21,97 \%)$. Spesies yang memiliki nilai dominansi terendah adalah Scyphiphora hydrophyllacea dengan nilai dominansi sebesar $92,96 \mathrm{~cm}^{2} / 100 \mathrm{~m}^{2}(2,45 \%)$.

Berdasarkan nilai kerapatan, frekuensi kehadiran, dan dominansi spesies, maka spesies Aegiceras floridum, Sonneratia alba, Ceriops tagal, dan Rhizophora stylosa merupakan spesies yang memiliki pertumbuhan yang baik pada pantai Negeri Tial,. Hal ini disebabkan substrat yang terdapat pada pantai Negeri Tial mendukung pertumbuhan jenis-jenis tersebut. Menurut Tomlinson, (1986); Rulisa, et al., (1999) dan Schaduw, (2019), jenis Ceriops tagal dan Rhizophora stylosa sangat menyukai substrat lempung dan sedikit tercampur dengan substrat berpasir. Sedangkan Sonneratia alba dan Aegiceras floridum dapat ditemukan pada substrat berpasir dan berbatu di daerah tepian sungai dan zona pasang surut pesisir. Jenis Sonneratia alba dan Aegiceras corniculatum di Negeri Ihamahu Saparua ditemukan pada substrat yang didominasi oleh substrat pasir halus hingga sedang (Lewerissa, $d k k ., 2018$ ).

Tabel 3. Jenis-jenis mangrove yang ditemukan pada pantai Negeri Tial

\begin{tabular}{ccc}
\hline Famili & Genus & Jenis \\
\hline & Bruguiera & Bruguiera gimnorrhiza (L.) Lamk. \\
Rhizophoraceae & Ceriops & Ceriops tagal (Perr.) C. B. Rob. \\
& Rhizophora & Rhizophora apiculata Bl. \\
& & Rhizophora stylosa Griff. \\
Myrsinaceae & Aegiceras & Aegiceras corniculatum (L.) Blanco \\
& Excoecaria & Aegiceras floridum R.\& S. \\
Euphorbiaceae & Excoecaria agallocha L. \\
Rubiceae & Scyphiphora & Scyphiphora hydrophyllacea Gaertn. F. \\
Sonneraticeae & Sonneratia & \\
& &
\end{tabular}


Tabel 4. Potensi mangrove pada pantai Negeri Tial

\begin{tabular}{|c|c|c|c|c|c|c|c|}
\hline No & Jenis & $\begin{array}{c}\mathrm{K} \\
\text { Ind/100m }\end{array}$ & $\mathbf{F}$ & $\begin{array}{c}D \\
\mathrm{Cm}^{2} / 100 \mathrm{~m}^{2}\end{array}$ & $\begin{array}{l}\text { KR } \\
\%\end{array}$ & $\begin{array}{l}\text { FR } \\
\%\end{array}$ & $\begin{array}{l}\text { DR } \\
\%\end{array}$ \\
\hline 1 & Rhizophora stylosa & 4,17 & 0,42 & 174,04 & 13,05 & 16,13 & 4,59 \\
\hline 2 & Sonneratia alba & 3,75 & 0,67 & 2298,75 & 11,75 & 25,81 & 60,67 \\
\hline 3 & Ceriops tagal & 6 & 0,50 & 295,07 & 18,80 & 19,35 & 7,79 \\
\hline 4 & Scyphiphora hydrophyllacea & 2,50 & 0,25 & 92,96 & 7,83 & 9,68 & 2,45 \\
\hline 5 & Aegiceras corniculatum & 2,50 & 0,17 & 95,48 & 7,83 & 6,45 & 2,52 \\
\hline 6 & Aegiceras floridum & 13 & 0,58 & 832,50 & 40,73 & 22,58 & 21,97 \\
\hline & Jumlah & 31,92 & 2,58 & 3788,79 & 100 & 100 & 100 \\
\hline
\end{tabular}

Tabel 5. Kondisi Komunitas Mangrove Pantai Tial

\begin{tabular}{cccc}
\hline $\begin{array}{c}\text { Tutupan Kanopi } \\
(\%)\end{array}$ & $\begin{array}{c}\text { Kerapatan } \\
\text { (Indv/ha) }\end{array}$ & Min & $\begin{array}{c}\text { INP } \\
(\boldsymbol{\%})\end{array}$ \\
\hline $71.34 \pm 11.79$ & $3191 \pm 1071$ & AC $: 16,80$ & Max \\
\hline Ket : Sonneratia alba (SA); Aegiceras corniculatum (AC); Indeks Nilai Penting (INP); Minimum & (Min); Maksimum (Max); individu (indv).
\end{tabular}

\section{Kondisi Komunitas Mangrove}

Berdasarkan hasil analisis kondisi kesehatan mangrove (Tabel 5), menunjukkan bahwa mangrove pantai Negeri Tial berada pada kondisi yang tegolong baik atau sehat dengan kondisi kerapatan jenis yang sangat padat

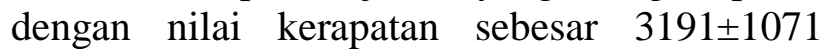
ind/ha dan kondisi tutupan kanopi yang tergolong sedang yaitu $71.34 \pm 11.79 \%$. Tutupan kanopi pada komunitas mangrove pantai Negeri Tial tergolong sedang meskipun kerapatan mangrove sangat padat. Hal ini disebabkan karena jenis Aegiceras floridum merupakan jenis paling dominan pada tingkat kerapatan jenis mangrove. Aegiceras floridum memiliki ukuran ranting yang kecil; serta pertumbuhan daun pada setiap ranting yang tidak terlalu lebat dan memiliki ukuran daun yang agak kecil, sehingga tutupan kanopi (ranting dan daun mangrove) tergolong sedang. Menurut Rusila, et al. (1999), jenis Aegiceras floridum merupakan semak atau pohon kecil yang selalu bertumbuh lurus setinggi $4 \mathrm{~m}$ dan memiliki ukuran daun sebesar 3-6 cm. Secara keseluruhan berdasarkan indeks nilai penting, jenis yang memiliki potensi adaptif paling tinggi pada pantai Negeri Tial yaitu Sonneratia alba dan yang paling rendah adalah jenis Aegiceras corniculatum.
Keberadaan kedua jenis mangrove ini perlu dijaga keberlanjutannya, mengingat lokasi Negeri Tial yang berhadapan langsung dengan lautan lepas. Fungsi ekologis mangrove yang berhubungan dengan mitigasi bencana menjadi penting untuk menjaga dan melindungi suatu daerah dari bencana (Vitasari, 2015). Oleh karena itu, kegiatan yang cenderung merusak dan berdampak negatif bagi pertumbuhan mangrove harus dihilangkan.

\section{KESIMPULAN DAN SARAN}

Perairan Pantai Tial memiliki sembilan spesies mangrove dimana Sonneratia alba dan Aegiceras floridum merupakan spesies yang dominan. Kondisi kesehatan mangrove pantai Tial masih dalam kondisi baik dengan kerapatan mangrove tergolong sangat padat dan tutupan kanopi tergolong sedang.

Perlu dilakukannya penelitian lanjutan untuk mengetahui aktivitas-aktivitas pemanfaatan dan parameter lingkungan lainnya yang mempengaruhi komunitas mangrove pantai Negeri Tial. Perlu adanya perhatian dari pemerintah Negeri Tial dalam mengelola komunitas mangrove yang masih sangat baik agar tetap terjaga. Perlu dilakukan kegiatan 
penanaman spesies mangrove yang sudah mulai terdegradasi atau sedikit kehadirannya.

\section{DAFTAR PUSTAKA}

Bengen, D.G 2001. Pedoman Teknis Pengenalan dan Pengelolaan Ekosistem Mangrove. Pusat Kajian Sumber daya Pesisir dan Lautan IPB.

Chianucci, F., U. Chiavetta, A. Cutini. 2014. The Estimation of Canopy Attributes from Digital Cover Photography by Two Different Image Analysis Methods. iForest-Biogeoscience and Forestry 7(4): 255-259.

Chrisyariati, I., B. Hendrarto, Suryanti. 2014. Kandungan Nitrogen Total dan Fosfat Sedimen Mangrove pada Umur yang Berbeda di Lingkungan Pertambakan Mangunharjo, Semarang. Diponegoro Journal of Marquares 3(3): 65-72.

DAI. 2018. Laporan Kajian Kerapatan dan Risiko Iklim Lanskap Pulau Ambon dan Kepulauan Lease. USAID. Fromhttp://www.apikindonesia.or.id

de Pannier R.F. \& Pannier F. 2008. Mangrove Restoration in a Tropical Semiarid Environment: A Case Study in Landscape Design. In: Lieth H., Sucre M.G., Herzog B. (eds) Mangroves and Halophytes: Restoration and Utilisation. Tasks for Vegetation Sciences, vol 43. Springer, Dordrecht. https://doi.org/10.1007/978-1-4020-67204_10.

Dharmawan, I.W.E. \& Pramudji. 2014. Panduang Monitoring Status Ekosistem Mangrove. Coremap CTI - LIPI, 35-11 pp

English, S., C. Wilkinson, \& V. Baker,. 1997. Survey Manual for Tropical Marine Resources 2nd Edition. Australian Institute of marine Science. Townsville.

FAO. 2007. The World's Mangroves 1980-2005. FAO Publisher. Rome. Italy

Giesen, W., S. Wulffraat, M. Zieren, L. Scholten. 2006. Mangrove Guidebook for Southeast Asia. FAO and Wetlands International. Bangkok.

Jenning, S.B., N.D. Brown, D. Sheil. 1999. Assessing Forest Canopies and Understorey Illumination: Canopy Closure, Canopy Cover and Other Measures. Forestry 72(1): 59-74.

Kitamura, S., C. Anwar, A. Chaniago, S. Baba. 1999. Handbook of Mangroves in Indonesia. Saritaksu. Denpasar, Indonesia.

Lewerissa, Y.A., M. Sangaji, M.B. Latumahina. 2018. Pengelolaan Mangrove Berdasarkan
Tipe Substrat di Perairan Negeri Ihamahu Pulau Saparua. TRITON: Jurnal Manajemen Sumberdaya Perairan 14(1): 1-9.

Lilimwelat, K.O., N. Retraubun, M.F. Telussa. 2019. Analisa Erosi Pantai Desa Seri Kecamatan Nusaniwe Kota Ambon. Jurnal Manumata 5(2): 85-94. ISSN 2087-5703.

Lugina, M., Indartik, A. Pribadi. 2019. Valuasi Ekonomi Ekosistem Mangrove dan Kontribusinya Terhadap Pendapatan Rumah Tangga: Studi Kasus Desa Pemogan, Tuban dan Kutuwaru. Jurnal Penelitian Sosial dan Ekonomi Kehutanan 16(3): 197-210. E-ISSN 2502-4221.

Menteri Negara LH. 2004. Keputusan Menteri Negara Lingkungan Hidup Nomor 201 Tentang Kriteria Baku dan Pedoman Penentuan Kerusakan Mangrove.

Madiama, S., C. Muryani, S. Santosa. 2016. Kajian Perubahan Luas dan Pemanfaatan Serta Persepsi Masyarakat Terhadap Pelestarian Hutan Mangrove di Kecamatan Teluk Ambon Baguala. Geoeco 2(2): 170-183.

Rusila N.Y., M. Khazali, I N. N. Suryadiputra. 1999. Panduan Pengenalan Mangrove Di Indonesia. PHKA/WI-IP, Bogor.

Sambah, A. B., D. Affandy, O. M. Luthfi, A. Efani. 2019. Identifikasi dan nalisis Potensi Wilayah Pesisir Sebagai Dasar Pemetaan Kawasan Konservasi di Pesisir Kabupaten Banyuwangi, Jawa Timur. Jurnal Ilmu Kelautan SUPERMONDE 5(2): 61-69. E-ISSN 26145049 .

Saru, A. 2014. Potensi Ekologis dan Pengelolaan Ekosistem Mangrove Di Wilayah Pesisir. IPB Press, Bogor.

Schaduw, J. N. W. 2019. Struktur Komunitas dan Presentase Penutupan Kanopi mangrove Pulau Salawati Kabupaten Kepulauan Raja Ampat Provinsi Papua Barat. Majalah Geografi Indonesia. Yogyakarta 33(1):26-34.

Sjafrie, N. D. M. 2016. Jasa Ekosistem Pesisir. Oseana XLI(4): 25-40. ISSN 0216-1877.

Spalding, M., F. Blasco, C. Field,. 2010. World Mangrove Atlas. UNEP-WCMC, Cambridge University Press.

Sudarto. 2011. Pemanfaatan dan Pengembangan Energi Angin Untuk Proses Produksi Garam di Kawasan Timur Indonesia. TRITON: Jurnal Manajemen Sumberdaya Perairan 7(2):61-70.

Suyadi. 2009. Kondisi Hutan Mangrove di Teluk Ambon: Prospek dan Tantangan. Berita Biologi 9(5): 481-490. ISSN 0126-1754.

Takarendehang, R., C. F. A. Sondak, E. Kaligis, D. Kumampung, I. S. Manembu, U. N. J. W. 
Rembet. 2018. Kondisi Ekonomi dan Nilai Manfaat Hutan Mangrove di Desa Lansa, Kecamatan Wori, Kabupaten Minahasa Utara. Jurnal Pesisir dan Laut Tropis 2(1): 45-52.

Tomlinson, P.B. 1986. The Botany of Mangroves. Cambridge University Press, Cambridge, U.K. $413 \mathrm{pp}$.

Vitasari, M. 2015. Kerentanan Ekosistem Mangrove Terhadap Ancaman Gelombang
Ekstrim/Abrasi di Kawasan Konservasi Pulau Dua Banten. Bioedukasi 8(2): 33-36.

Wattimena, J.D \& M. R. Ayal. 2018. Analisis Perubahan Garis Pantai Desa Rutong Kota Ambon. Jurnal Teknik Sipil 14(2): 115-136.

Widagdo, R. F. \& A. Sugiri. 2014. Kajian Pengendalian dalam Mengatasi Kerusakan Ekosistem Mangrove di Kawasan Pesisir Kabupaten Pekalongan. Jurnal Teknik PWK 3(2): 285-294. 